\title{
THE EFFECT OF GAMMA IRRADIATION ON THE GERMINATION AND GROWTH OF TURDA STAR MAIZE HYBRID DRY SAMPLES
}

\author{
Marcu Delia, Cosma Constantin \\ Faculty of Environmental Science, „Babes-Bolyai” University, Fantanele Street No.30, Cluj-Napoca, Romania \\ E-mails: delia.marcu@yahoo.com
}

\begin{abstract}
In order to study the effects of gamma rays on germination indices i.e. germination index (GI), total germination (GT) and the germination energy $(G E)$, of maize hybrid, Turda Star current experiment was conducted. Dry seeds of Turda Star maize hybrid were irradiated with 2, 5, 15, 30 and $50 \mathrm{~Gy}$, using $a^{60}$ Co-gamma radiation source.

Results showed that gamma irradiation affected all the above mentioned parameters except germination percentage. Total germination and germination energy was significantly affected at higher doses of gamma rays. However, increasing doses of gamma rays did not have significant effects on seed germination percentage. The other growth parameters showed declining tendency with increasing doses of gamma irradiation.
\end{abstract}

Keywords: gamma ray, maize hybrid, seed germination

\section{INTRODUCTION}

Nuclear techniques, in contrast to conventional breeding techniques, are widely applied in agriculture for improving genetical diversity. Unlike conventional breeding procedures which involve, the production of new genetic combinations from already existing parental genes, nuclear technology causes exclusively new gene combinations with high mutation frequency. Basic tool of nuclear technology for crop improvement is the use of ionizing radiation which causes induced mutations in plants. These mutations might be beneficial and have higher economical values.

Gamma rays generally influence plant growth and development by inducing cytological, genetical, biochemical, physiological and morphogenetic changes in cells and tissues (Gunckel \& Sparrow, 1961). There are some reports which showed that the higher exposures of gamma rays were usually inhibitory (Bora, 1961; Radhadevi \& Nayar, 1996; Kumari \& Singh, 1996), whereas lower exposures were sometimes stimulatory (Torne \& Desai 1965; Taylor, 1968; Sparrow, 1966; Mujeeb \& Greij, 1976; Mathew \& Gaur, 1975; Raghava \& Raghava, 1989; Thapa, 1999). (Majeed et al., 2010)

Gamma rays are the most energetic form of electromagnetic radiation, possesses the energy level from $10 \mathrm{keV}$ to several hundred kiloelectron volts, and they are considered as the most penetrating in comparison to other radiation such as alpha and beta rays (Kovacs \& Keresztes, 2002). Gamma rays belong to ionizing radiation and interact on atoms or molecules to produce free radicals in cells. These radicals can damage or modify important components of plant cells and have been reported to affect differentially the morphology, anatomy, biochemistry and physiology of plants depending on the irradiation level. These effects include changes in the plant cellular structure and metabolism e.g., dilation of thylakoid membranes, alteration in photosynthesis, modulation of the antioxidative system and accumulation of phenolic compounds (Kim et al., 2004, Wi et al., 2005). (Ikram et al., 2010)

The objectives of the present investigation were to (i) treat the seeds of Turda Star maize hybrid with gamma rays $\left({ }^{60} \mathrm{Cobalt}\right)$ and (ii) evaluate the seed germination and various growth parameters of this hybrid maize.

The vegetal material, represented by maize, was chosen due to its agricultural and economic contribution. Maize has been a model species for researchers since it became the first plant to have a genetic map, published in 1935. (Bennetsen, Hake, ). The hybrid used in this study has been registered in 2005 at the Agricultural research and development station Turda, Romania.

\section{MATERIALS AND METHODS}

Dry seeds of Turda Star maize hybrid were treated with different doses of gamma rays irradiated with different doses of gamma rays $(2,5,15,30$ and $50 \mathrm{~Gy})$, using a ${ }^{60} \mathrm{Co}$ gamma radiation source emitting at $5,72 \mathrm{~Gy} / \mathrm{h}$ rate at Babes-Bolyai University, Physics Faculty, from Cluj- Napoca, Romania.

The Turda Star maize hybrid seeds were obtained from Agricultural research and development station Turda, Romania. Samples of 40 dry seeds were packed in polyethylene bags, labeled and identified with its respective irradiation doses. The germination was performed in laboratory conditions. Seeds were placed 
trays containing humidified filter paper, at $21^{\circ} \mathrm{C}$ room temperature. Growth parameters, both on the control and irradiated seedlings, were recorded daily for 7 days.

The considered parameters for the collected data are: germination index $(\mathrm{GI})$, total germination $\left(\mathrm{G}_{\mathrm{T}}\right)$ and the germination energy (GE) calculated as follows:

$$
\mathrm{GI}=\mathrm{N}_{1} / 1+\mathrm{N}_{2} / 2+\mathrm{N}_{3} / 3 \ldots \ldots \ldots+\mathrm{N}_{\mathrm{n}} / \mathrm{N}
$$

where $\mathrm{N}_{1}, \mathrm{~N}_{2}, \mathrm{~N}_{3}, \mathrm{~N}_{\mathrm{n}}$ : number of seeds which germinated in day 1, 2,3...,n (Dezfuli et al., 2008)

$$
G_{T}=\frac{N_{T} \times 100}{N}
$$

with $\mathrm{N}_{\mathrm{T}}$ : proportion of germinated seeds in each treatment for the final measurements; $\mathrm{N}$ : number of seeds used in bioassay (Anjum es Bajwa., 2005)

$$
\mathrm{S}=\left(\mathrm{N}_{1} \mathrm{x} 1\right)+\left(\mathrm{N}_{2}-\mathrm{N}_{1}\right) 1 / 2+\left(\mathrm{N}_{3}-\mathrm{N}_{2}\right) 1 / 3+\ldots . .+\left(\mathrm{N}_{\mathrm{n}}-\mathrm{N}_{\mathrm{n}-1}\right) 1 / \mathrm{n}
$$

where $\mathrm{N}_{1}, \mathrm{~N}_{2}, \mathrm{~N}_{\mathrm{n}}, \mathrm{N}_{\mathrm{n}-1}$ : proportion of germinated seeds observed at $1,2,3, \ldots \mathrm{n}-1, \mathrm{n}$ days (Swaminathan et al., 1992)

All experiments were repeated there times (40 seeds replication). Collected data (both irradiated and non-irradiated) was subjected to One-way ANOVA test, using GraphPadPrism software.

\section{RESULTS AND DISCUSSION}

This investigation was carried out to study the relation between different doses of gamma radiation, seed germination and development of maize hybrid Turda Star.

The calculated germination index shows that the numbers of germinated seed/day in the irradiated samples is enhanced with $20 \%$ for $2 \mathrm{~Gy}, 18 \%$ for $5 \mathrm{~Gy}, 25 \%$ for $15 \mathrm{~Gy}, 6 \%$ for $30 \mathrm{~Gy}$ and $28 \%$ for $50 \%$ comparing with the control (Fig.1). The statistical analysis of the germination index revealed that the differences between the control and the irradiated samples are not significant

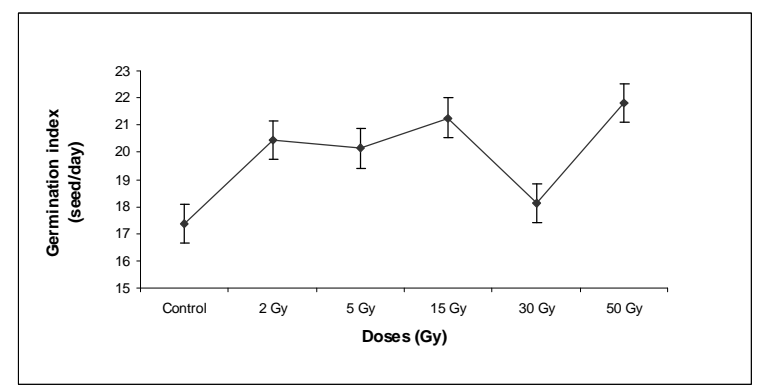

Figure 1. Germination index (seed/day)

The total germination percentage was increased at doses of 2 Gy with $5 \%, 5$ Gy with $2.5 \%$, at 15 Gy with $13 \%$ and at 50 Gy with $5 \%$, while at 30 Gy the percentage of germination was decreased with $6 \%$. Semnificative differences were observed between control and 15 Gy sample, 2 Gy and 30 Gy samples and 15 Gy and 30 Gy samples. (Figure 2)

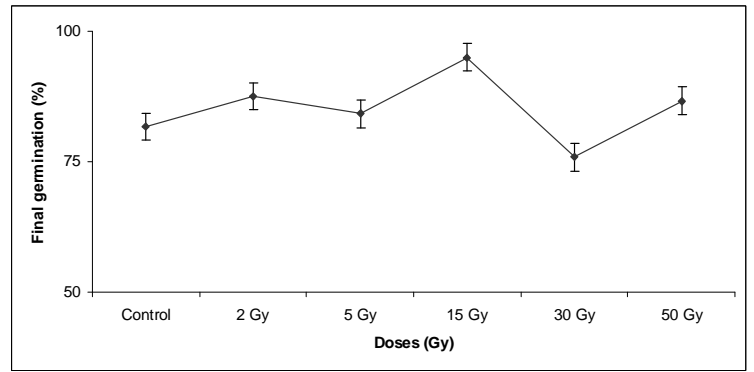

Figure 2. Total percent (\%) 
Germination energy is used as a measure of the speed germination. This parameter shows a linear increase up to $15 \mathrm{~Gy}$, at $30 \mathrm{~Gy}$ it shows a sudden decrease and then is increasing up to $50 \mathrm{~Gy}$. The differences between $30 \mathrm{~Gy}$ and $15 \mathrm{~Gy}$, respectively $50 \mathrm{~Gy}$, are statistical semnificative.

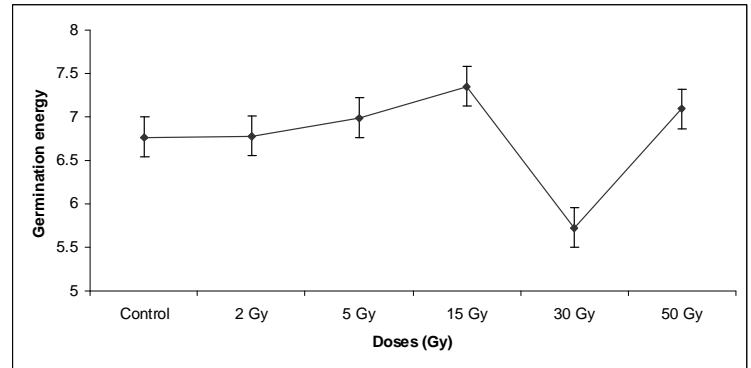

Figure 3. Germination energy

The growth parameters analyzed in this study reveals that seed irradiation prior sowing can affect the growth and development of the seedlings.

\section{REFERENCES}

1. Abdul Majeed, Asif Ur Rehman Khan, Habib Ahmad, Zahir Muhammad, Gamma irradiation effects on some growth parameters of Lepidium sativum L., ARPN Journal of Agricultural and Biological Science, Vol. 5, No. 1, January 2010, 39-42

2. Naheed Ikram, Shahnaz Dawar, Zeeshan Abbas, M. Javed Zaki, Effect of (60cobalt) gamma rays on growth and root rot diseases in mungbean (Vigna Radiata L.), Pak. J. Bot., 42(3): 2165-2170, 2010

3. Marie-Andrée Esnault, Florence Legue, Christian Chenal, Ionizing radiation: Advances in plant response, Environ. Exp. Bot. (2010)

4. S. B. Preuss, A. B. Britt, A DNA damage induced cell cycle checkpoint in Arabidopsis, Genetics 164: $323-334$ (May 2003)

5. R.J. Camargoa, C.C. Tadinib, S.F. Sabato, Physical-chemical analyses of irradiated papayas (Carica papaya L.), Radiation Physics and Chemistry 76 (2007) 1866-1868

6. Maria Emilia Latorre, Patricia Narvaiz, Ana María Rojas, Lía Noemí Gerschenson, Effects of gamma irradiation on biochemical and physico-chemical parameters of fresh-cut red beet (Beta vulgaris L. var. conditiva) root, Journal of Food Engineering 98 (2010) 178-191

7. Mohammad Alothman, Rajeev Bhat, A.A. Karim, Effects of radiation processing on phytochemicals and antioxidants in plant produce, Trends in Food Science \& Technology 20 (2009) 201-212

8. Seung Gon Wi, Byung Yeoup Chung, Jae-Sung Kim, Jin-Hong Kim, Myung-Hwa Baek, Ju-Woon Lee, Yoon Soo Kim, Effects of gamma irradiation on morphological changes and biological responses in plants, Micron 38 (2007) 553-564

9. J.P. Maitya, D. Mishraa, A. Chakrabortya, A. Sahaa, S.C. Santrab, S. Chandac, Modulation of some quantitative and qualitative characteristics in rice (Oryza sativa L.) and mung (Phaseolus mungo L.) by ionizing radiation, Radiation Physics and Chemistry 74 (2005) 391-394

10. William F. Grant, Elizabeth T. Owens, Zea mays assays of chemical/radiation genotoxicity for the study of environmental mutagens, Mutation Research 613 (2006) 17-64

11. J. A. da Costa-Nunes, A. M. Bhatt, S. O'Shea, C. E. West, C. M. Bray, U. Grossniklaus, H. G. Dickinson, Characterization of the three Arabidopsis thaliana RAD21 cohesins reveals differential responses to ionizing radiation, Journal of Experimental Botany, Vol. 57, No. 4, pp. 971-983, 2006

12. Bennetsen Jess, Sarah Hake, Handbook of maize: Genetics and genomics, Springer Science + Business Media

13. Pegah Moradi Dezfuli, Farzad Sharif-zadeh, Mohsen Janmohammadi, Influence of priming techniques on seed germination behavior of maize inbred lines (Zea mays L.), Vol. 3, No. 3, May 2008 ISSN 1990-6145 ARPN Journal of Agricultural and Biological Science

14. Tehmina Anjum, Rukhsana Bajwa, Importance of Germination Indices in Interpretation of Allelochemical Effects, International journal of agriculture \&biology 1560-8530/2005/07-3-417-419

15. C. Swaminathan, R.S. Vinaya Rai, K. K. Suresh, K. Sivaganam, Improving seed germination of derris indica by vertical sowing, Journal of Tropical Forest Science 6(2): 152-158, 1992 